\title{
Can extra protamine eliminate heparin rebound following cardiopulmonary bypass surgery?
}

\author{
Kevin H. T. Teoh, MDa \\ Edward Young, $\mathrm{PhD}^{\mathrm{b}}$ \\ Mary Helen Blackall, $\mathrm{RN}^{\mathrm{a}}$ \\ Robin S. Roberts, MTech ${ }^{\mathrm{C}}$ \\ Jack Hirsh, MD ${ }^{\mathrm{d}}$
}

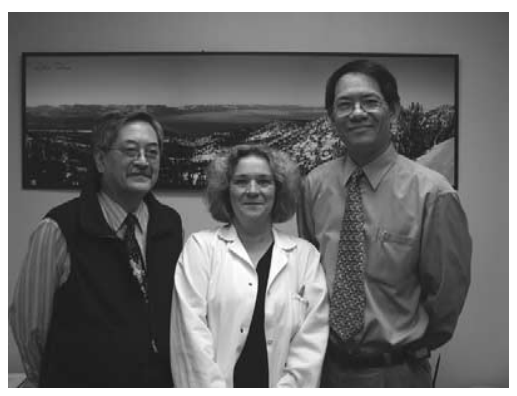

Left to right: Young, Blackall, and Teoh
From the Departments of Surgery, ${ }^{\text {a Pathol- }}$
ogy and Molecular Medicine, ${ }^{\mathrm{b}}$ Clinical Ep-
idemiology and Biostatistics, ${ }^{\mathrm{c}}$ and Medi-
cine, ${ }^{\mathrm{d}}$ McMaster University, and the
Henderson Research Centre, Hamilton, On-
tario, Canada.

Supported by a grant from the Canadian Institutes of Health Research.

Received for publication Aug 7, 2003; revisions received Dec 3, 2003; accepted for publication Dec 11, 2003.

Address for reprints: Edward Young, PhD, Hamilton Regional Laboratory Medicine Program, Henderson General Hospital Site, 711 Concession Street, Hamilton, Ontario, Canada L8V 1C3 (E-mail: younged@ hhsc.ca).

J Thorac Cardiovasc Surg 2004;128:211-9

$0022-5223 / \$ 30.00$

Copyright $\odot 2003$ by The American Association for Thoracic Surgery

doi:10.1016/j.jtcvs.2003.12.023
Objectives: Heparin rebound, the reappearance of anticoagulant activity after adequate neutralization with protamine, is thought to contribute to excessive postoperative bleeding after cardiac surgery. We have previously demonstrated that a significant amount of heparin is bound nonspecifically to plasma proteins and is incompletely neutralized by protamine. The aim of this study was to investigate whether clinically important bleeding attributable to heparin rebound can be eliminated by infusion of small amounts of additional protamine for 6 hours postoperatively and whether this treatment can reduce mediastinal blood loss.

Methods: Three hundred patients undergoing elective cardiac surgery were randomized to receive either a continuous infusion of protamine sulphate $(25 \mathrm{mg} / \mathrm{h}$ for 6 hours) postoperatively or saline placebo. Serial blood samples were obtained to measure thrombin clotting time and anti-factor Xa activity. Heparin bound nonspecifically to plasma proteins was measured after displacement with a chemically altered heparin with low affinity to antithrombin. Mediastinal blood loss and transfusion requirements were recorded.

Results: Heparin rebound was demonstrated in every patient in the placebo group as reflected by increased thrombin clotting time, anti-factor Xa activity, and proteinbound heparin between 1 and 6 hours after surgery. In contrast, heparin rebound was eliminated in the protamine infusion group. The thrombin clotting time was normalized and both heparin concentration and protein-bound heparin were almost undetectable $(P<.001)$. There was a modest $13 \%$ reduction in postoperative bleeding but this did not reduce blood transfusions. No adverse events were attributable to the extra protamine.

Conclusions: Postoperative protamine infusion was able to almost totally abolish heparin rebound. In the context of this study, protamine infusion resulted in reduced postoperative bleeding but the magnitude was insufficient to alter transfusion requirements.

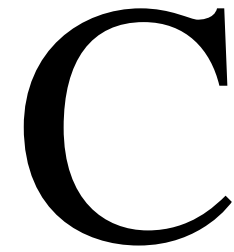
ardiopulmonary bypass is an integral component of cardiac surgery. Patients undergoing cardiopulmonary bypass surgery who have significant bleeding after cardiac surgery are at risk of increased mortality and morbidity. Protamine sulphate is administered after cardiopulmonary bypass to neutralize the anticoagulant effect of heparin, thereby establishing normal hemostasis after surgery. Hyun and associates ${ }^{1}$ described the reappearance of hypocoagulability after adequate neutralization of heparin and coined the phrase "heparin rebound" to describe this phenomenon. Gollub ${ }^{2}$ noted that the prolongation of clotting times postoperatively after initial neutralization could be shortened by the administration of additional protamine and concluded that the phenomenon was caused by reap- 
TABLE 1. Patient characteristics of the study groups

\begin{tabular}{lcc}
\hline & Protamine & Placebo \\
\hline Number of patients & 152 & 148 \\
Age (y) & $62 \pm 10$ & $61 \pm 9.7$ \\
Men/women (\%) & $79 / 21$ & $76 / 24$ \\
Body surface area $\left(\mathrm{m}^{2}\right)$ & $1.96 \pm 0.18$ & $1.92 \pm 0.19$ \\
CABG/valves (\%) & $88 / 12$ & $88 / 12$ \\
Combined CABG and valves & 0 & 0 \\
Cardiopulmonary bypass time (min) & $88 \pm 27$ & $85 \pm 28$
\end{tabular}

$C A B G$, Coronary artery bypass grafting.

Values are mean $\pm S D$.

pearance of heparin in the circulating blood. The reported incidence of heparin rebound varies widely and has been reported to be as high as $50 \%$. $^{3}$

The anticoagulant activity of heparin is mediated by its binding through a specific pentasaccharide to antithrombin (AT), which results in a marked accceleration of the rate at which AT inactivates thrombin, factor Xa, and other serine proteases in the coagulation cascade. ${ }^{4}$ Heparin also binds nonspecifically and independently of the pentasaccharide to other plasma proteins, platelet-derived proteins, and tissue and cellular sites. ${ }^{5,6}$

We developed a probe that displaces heparin from plasma proteins, which allows us to determine the role of heparin-binding proteins in the mechanism of heparin rebound. We have prepared a heparin with virtually no affinity to AT by chemical modification. ${ }^{7}$ When added in excess to plasma, this low-affinity heparin is able to displace anticoagulantly active heparin from plasma proteins, which is then measured in an anti-factor Xa heparin assay. ${ }^{8}$ In a previous study, ${ }^{9}$ we employed this low-affinity heparin to study heparin rebound in 16 patients undergoing elective cardiac surgery. After neutralization with protamine sulphate the activated clotting time returned to baseline values. However, heparin activity measured as anti-factor Xa activity was consistently elevated for the first 6 hours postoperatively. Anti-factor Xa activity after the addition of lowaffinity heparin to displace protein-bound heparin was measurable in all patients and was 3- to 4-fold greater, indicating that a pool of heparin remained in the circulation for a number of hours postoperatively despite reversal with protamine sulphate. Postoperative blood loss correlated with postoperative heparin anticoagulant activity, suggesting that the heparin that remained after protamine sulphate neutralization was sufficient to impair hemostasis and promote postoperative hemorrhage.

Excessive postoperative hemorrhage continues to complicate cardiac surgery. Bleeding is caused by a combination of incomplete surgical hemostasis and an acquired hemostatic defect. ${ }^{10}$ The nature of the acquired hemostatic defect has been the subject of considerable controversy. The contribution of heparin rebound to postoperative bleeding has
TABLE 2. Adverse events

\begin{tabular}{lrcc}
\hline Outcome & Protamine & Placebo & $\boldsymbol{P}$ \\
\hline Reoperation for bleeding & $1(0.7 \%)$ & $2(1.3 \%)$ & \\
Protamine given for bleeding & $12(7.9 \%)$ & $32(21.6 \%)$ & $<.001$ \\
Myocardial infarction & $2(2.6 \%)$ & $3(2.0 \%)$ & \\
Mortality & $2(1.3 \%)$ & $1(0.7 \%)$ & \\
Deep vein thrombosis/pulmonary & 0 & 0 & \\
$\quad$ embolus/stroke & & & \\
\hline
\end{tabular}

not been elucidated. Our studies have provided a plausible explanation for the mechanism for heparin rebound and have suggested a strategy for its elimination. One approach to reduce postoperative bleeding would be to use a continuous infusion of protamine after surgery to inactivate the heparin that dissociates from cellular and protein binding sites. The adverse cardiovascular effects of protamine ${ }^{11}$ should be minimal if the protamine is infused at a slow rate. The aim of the present study was to determine whether heparin rebound can be eliminated by additional treatment with protamine sulphate for 6 hours postoperatively and whether this protocol can result in the reduction in postoperative bleeding.

\section{Methods}

\section{Trial Design and Patient Population}

The study was conducted as a double-blind, randomized trial. Three hundred patients undergoing elective cardiac surgery were enrolled in the preoperative clinic over a period of 12 months. These patients signed a consent form that was approved by the Institutional Review Board. Patients were randomized by the pharmacist to receive either a continuous intravenous infusion of protamine sulphate $(25 \mathrm{mg} / \mathrm{h})$ for 6 hours postoperatively or saline placebo according to a randomization table. The protamine dose was chosen based on a pilot study that showed $25 \mathrm{mg} / \mathrm{h}$ markedly reduced heparin levels over this time interval. Our earlier study ${ }^{9}$ suggested that the infusion should be given for at least 6 hours after surgery. The primary outcome of the study was clinically important postoperative bleeding that we defined as the need for transfusion of 4 or more units of blood. The secondary outcome was postoperative mediastinal blood loss. Our sample size estimates suggested that 150 patients/group would have a $90 \%$ power of detecting a $50 \%$ reduction in patients requiring 4 or more units of blood transfusion with an alpha of .05 in a 2-tailed test.

\section{Heparin and Protamine Management}

Heparin (Hepalean; Organon Teknika, Toronto, Canada) was given at an initial dose of $400 \mathrm{U} / \mathrm{kg}$ to achieve an activated clotting time (ACT) greater than 400 seconds. Cardiopulmonary bypass was instituted with an ascending aortic cannula and a 2-stage right atrial cannula in most patients. The pump circuit employed a semi-porous membrane oxygenator and was primed with Ringer's lactate solution. Moderate systemic hypothermia $\left(28^{\circ} \mathrm{C}-32^{\circ} \mathrm{C}\right)$ was maintained during the aortic crossclamp period. After discontinuation of cardiopulmonary bypass, heparin was reversed with a bolus of protamine sulphate using the heparin-ACT dose-response 


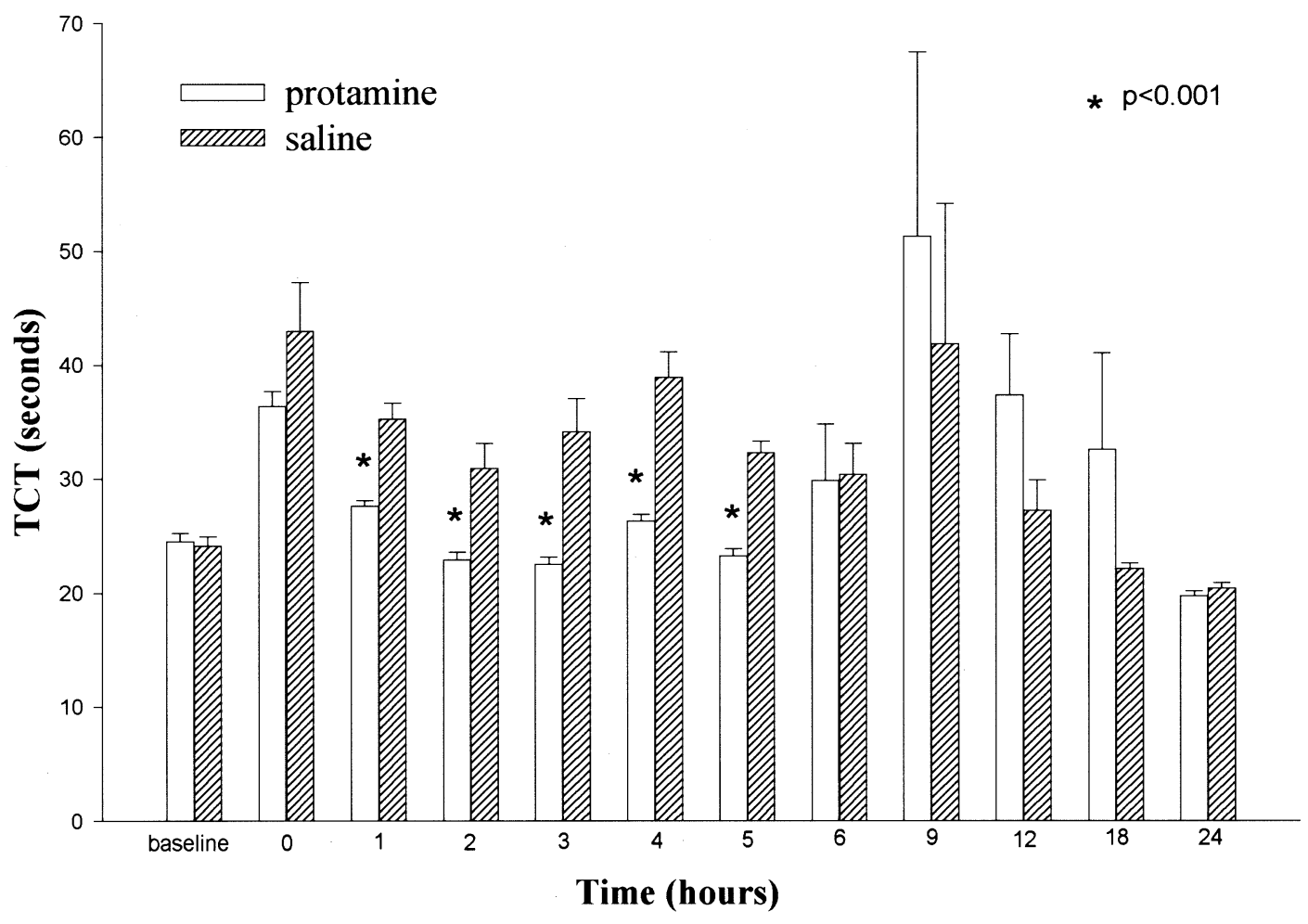

Figure 1. The effect of protamine infusion on the thrombin clotting time (TcT). Data are expressed as mean \pm SEM.

curve method to determine the dosage of protamine. Additional small doses of protamine were administered in some patients to return the ACT to preheparin values. The infusion of the test solution was initiated within 15 minutes of protamine reversal.

\section{Postoperative Management}

Patients enrolled in the study followed standardized guidelines for volume replacement and blood transfusions. The pulmonary capillary wedge pressure was maintained at appropriate levels by infusions of albumin or crystalloid. Hemoglobin concentrations were obtained at $1,3,12$, and 24 hours postoperatively. Packed red cells were transfused to maintain the hemoglobin between 80 and $90 \mathrm{~g} / \mathrm{L}$. Blood loss through the mediastinal tubes was measured and reinfused into the patient for up to 12 hours postoperatively. Aliquots of the drainage fluid were taken for hematocrit determinations using standard techniques. Clinically significant coagulation defects were treated by infusions of protamine, fresh-frozen plasma, or platelets when chest tube drainage fluid exceeded 150 $\mathrm{mL} / \mathrm{h}$. We employed the following guidelines for clinically significant defects: for extra protamine, thrombin clotting times (TcT, 2 units) $>35$ seconds; for plasma, an international normalized ratio $>1.5$; and for platelets, a count of $<80,000$. Pharmacological agents such as aprotinin, aminocaproic acid, and desmopressin were not employed in the patients.

\section{Anticoagulant Assays}

A baseline blood sample was collected from the radial arterial line prior to heparin administration. Timed blood samples were ob- tained hourly between 1 and 6 hours and at 12, 18, and 24 hours after protamine reversal also through the radial arterial line. Blood was collected into tubes containing buffered sodium citrate (Vacutainer, Becton Dickinson, Mississauga, Canada). Platelet-poor plasma (PPP) was prepared by centrifugation at $2000 \mathrm{~g}$ at room temperature for 15 minutes. The PPP was stored in polypropylene tubes at $-70^{\circ} \mathrm{C}$ until used.

Heparin concentrations were measured as anti-factor Xa activity based on the method of Teien and Lie. ${ }^{12}$ The Stachrom heparin kit from Diagnostica Stago (Wellmark Diagnostics, Guelph, Canada) was modified for use on the Cobas Bio centrifugal analyzer (Roche Diagnostics, Etobicoke, Canada). Pooled PPP to which known concentrations of unfractionated heparin (Hepalean, Organon Teknika) were added were used as standards. TcTs (2 units) were performed on the LaBor Coa System (Fisher Scientific, Toronto, Canada) using bovine thrombin (Thrombostat; ParkeDavis, Scarborough, Canada). All anticoagulant assays were performed in duplicate.

Low-affinity heparin was used as a probe to determine the extent to which anticoagulantly active heparin binds to plasma proteins other than AT. Low-affinity heparin was prepared from unfractionated porcine mucosal heparin (178 IU/mg, Sigma Chemical Co, St Louis, Mo) by periodate oxidation and borohydride reduction according to the method of Casu and colleagues ${ }^{13}$ with minor modifications. ${ }^{7}$ This chemical modification destroys the ability of unfractionated heparin to bind to AT but preserves the molecular size range and charge density of the parent molecule. The low-affinity heparin measured $<1.0 \mathrm{U} / \mathrm{mg}$ of anti-factor Xa 


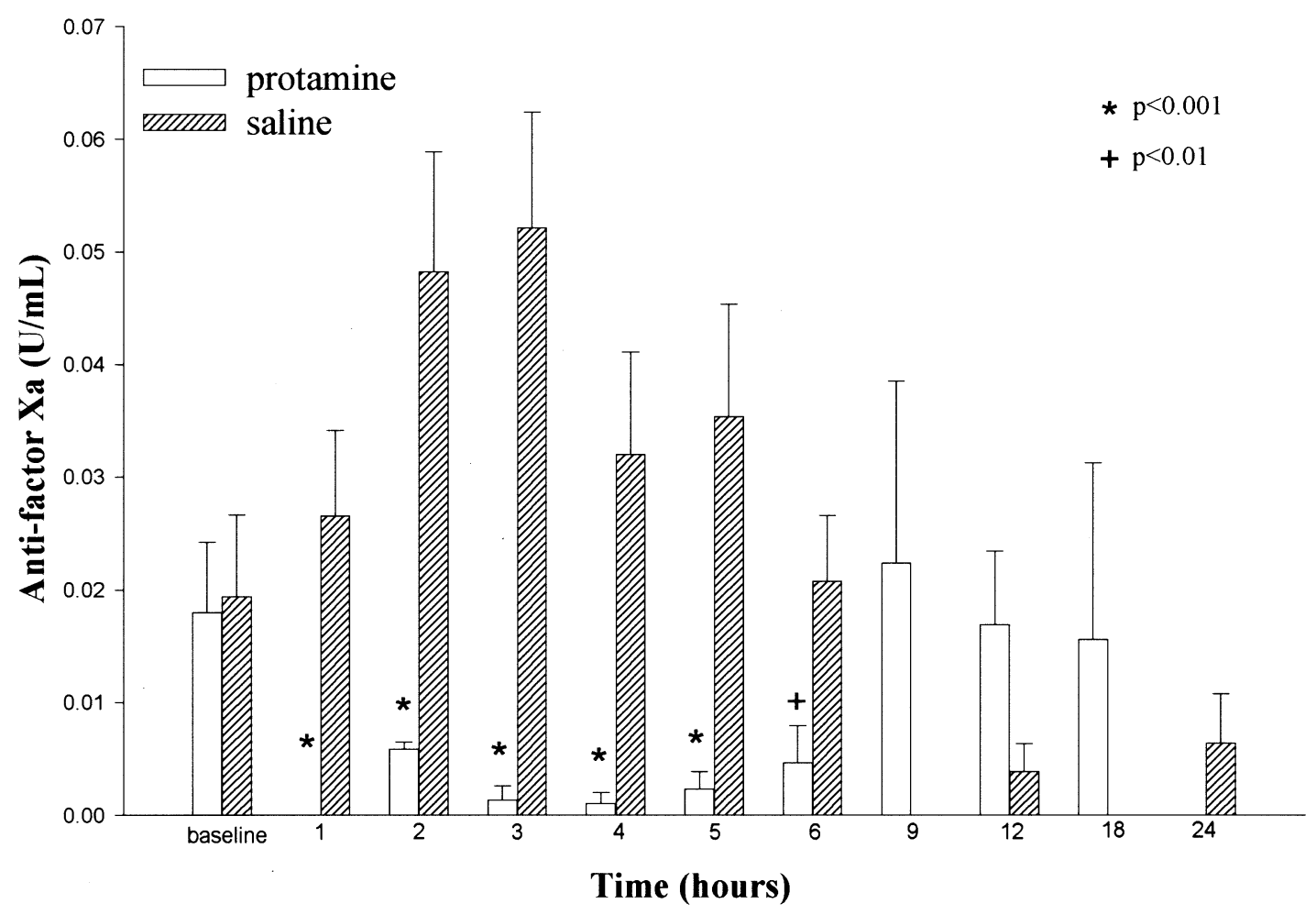

Figure 2. The effect of protamine infusion on heparin levels. Heparin was measured as anti-factor Xa activity. Data are expressed as mean \pm SEM.

activity. Excess low-affinity heparin was added to PPP at a concentration of $45 \mathrm{ug} / \mathrm{mL}$ to displace anticoagulantly active heparin from plasma protein binding $\operatorname{sites}^{8}$ and the anti-factor Xa activity was measured again. This in vitro assay may not reflect the amount of heparin bound to endothelium in vivo.

\section{Statistics}

Chi-square analysis was used to analyze categorical data. An independent 2-sample $t$ test was employed to analyze continuous data. Results are expressed as mean \pm standard deviation unless otherwise indicated.

\section{Results}

\section{Patient Characteristics}

A total of 152 patients were randomized to receive extra protamine $(25 \mathrm{mg} / \mathrm{h})$ for 6 hours postoperatively and 148 received saline placebo. The patient characteristics are shown in Table 1. No important differences in patient characteristics were found between the treatment and placebo groups.

The amount of heparin employed was 33,000 \pm 5000 units in the protamine group, which was not significantly different from 33,000 \pm 6000 units in the placebo group $(P$ $=.476$ ). Similarly, there was no difference between the amount of protamine required to return the ACT to preheparin levels prior to the infusion of the test solutions $(167 \pm$
$44 \mathrm{mg}$ in the protamine group vs $172 \pm 42 \mathrm{mg}$ in the placebo group, $P=.297$ ).

There were no adverse events attributable to the extra protamine administered postoperatively over 6 hours. No important differences were detected in the rate of reoperation, myocardial infarction, or mortality between the two groups. However, the number of patients requiring small amounts of protamine to control excessive bleeding was higher in the placebo group (Table 2). Most patients received 25 to $50 \mathrm{mg}$ of protamine.

\section{Reappearance of Anticoagulant Activity (Heparin Rebound)}

Despite returning the ACT to baseline levels following surgery, there was reappearance of anticoagulant activity indicative of heparin rebound as demonstrated by both the TcT and anti-factor Xa assay in the placebo group. As shown in Figure 1, the postoperative TcTs of the placebo group were consistently higher than that of the treatment group between 1 and 5 hours. In contrast, the TcTs of the group that received the extra protamine were within normal reference intervals (20-30 seconds) and significantly lower $(P<.001)$ for the same time frame. Unexpectedly, once the infusion of extra protamine was stopped, the TcTs became higher in the treatment group between 9 and 18 hours 


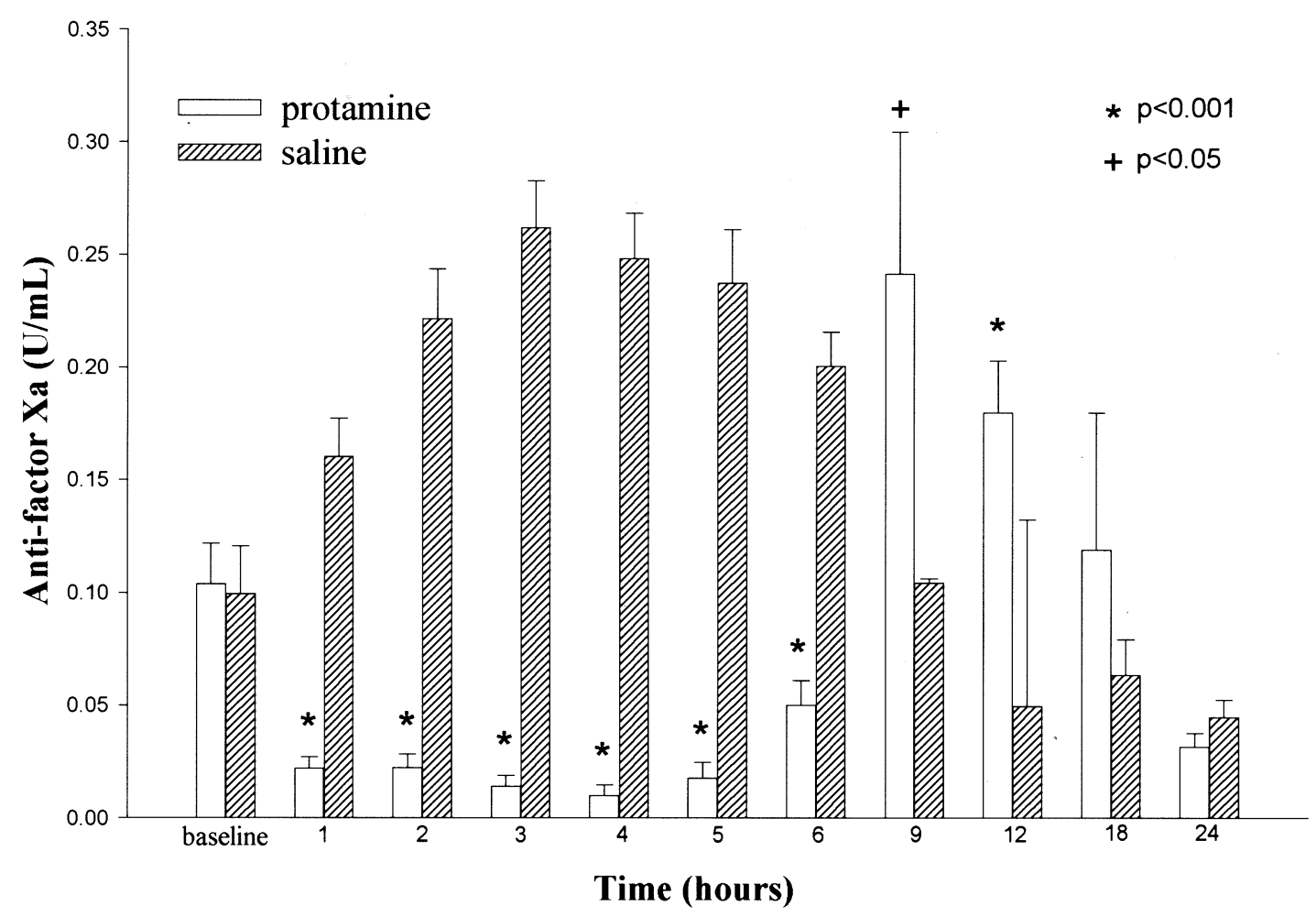

Figure 3. The effect of protamine infusion on heparin bound nonspecifically to plasma proteins. Low-affinity heparin was used to displace anticoagulantly active heparin from plasma protein binding sites. Data are expressed as mean $\pm \mathrm{SEM}$.

postoperatively, although this trend was not significant. Activated partial thromboplastin times (APTTs) were measured at 1 and 4 hours postoperatively as part of regular patient care. The APTT values in the placebo group were significantly higher than in the protamine group at 1 and 4 hours $(40.5 \pm 13.5$ seconds vs $32 \pm 5.2$ seconds at 1 hour, $P<.001$, and $38.0 \pm 13.5$ seconds vs $27.8 \pm 13.5$ seconds at 4 hours, $P<.001$ ).

Heparin concentrations measured as anti-factor Xa activity are shown in Figure 2. In the placebo group, heparin levels were elevated at 1 hour post-protamine neutralization and remained so for 6 hours (between 0.03 and $0.05 \mathrm{U} / \mathrm{mL}$ ). In contrast, the heparin concentrations in the group who received extra protamine were virtually undetectable (less than $0.002 \mathrm{U} / \mathrm{mL})$ and significantly lower $(P<.001)$ than that of the placebo group. The baseline samples were taken from the radial arterial line that was flushed with a solution containing small amounts of heparin. This explains the measurable anti-factor Xa levels found in these samples. The reappearance of small amounts of heparin following the cessation of the infusion of extra protamine was also detected by anti-factor Xa levels between 9 and 18 hours postoperatively.

\section{Protein-Bound Heparin}

Low-affinity heparin was added to the samples to determine the amount of anticoagulantly active heparin bound nonspecifically to plasma proteins other than AT. As shown in Figure 3, there was significantly more heparin bound to plasma proteins in the placebo group compared with the protamine group during the first 6 hours. Whereas the antifactor Xa levels in the placebo group reached peak levels of $0.25 \mathrm{U} / \mathrm{mL}$ at 3 and 4 hours, the levels found in the protamine group were consistently below $0.05 \mathrm{U} / \mathrm{mL}$. These results indicate that the infusion of additional protamine was able to reduce dramatically both free and protein-bound heparin. Once the infusion of additional protamine was stopped, the amount of heparin bound to plasma proteins became higher in the treatment group between 9 and 18 hours. This observation is consistent with the increased TcTs and anti-factor Xa levels described above.

\section{Blood Loss}

The infusion of extra protamine for 6 hours postoperatively was able to reduce mediastinal blood loss. As shown in Figure 4, A, the hourly blood loss in the protamine group was generally lower than the placebo group at all time 

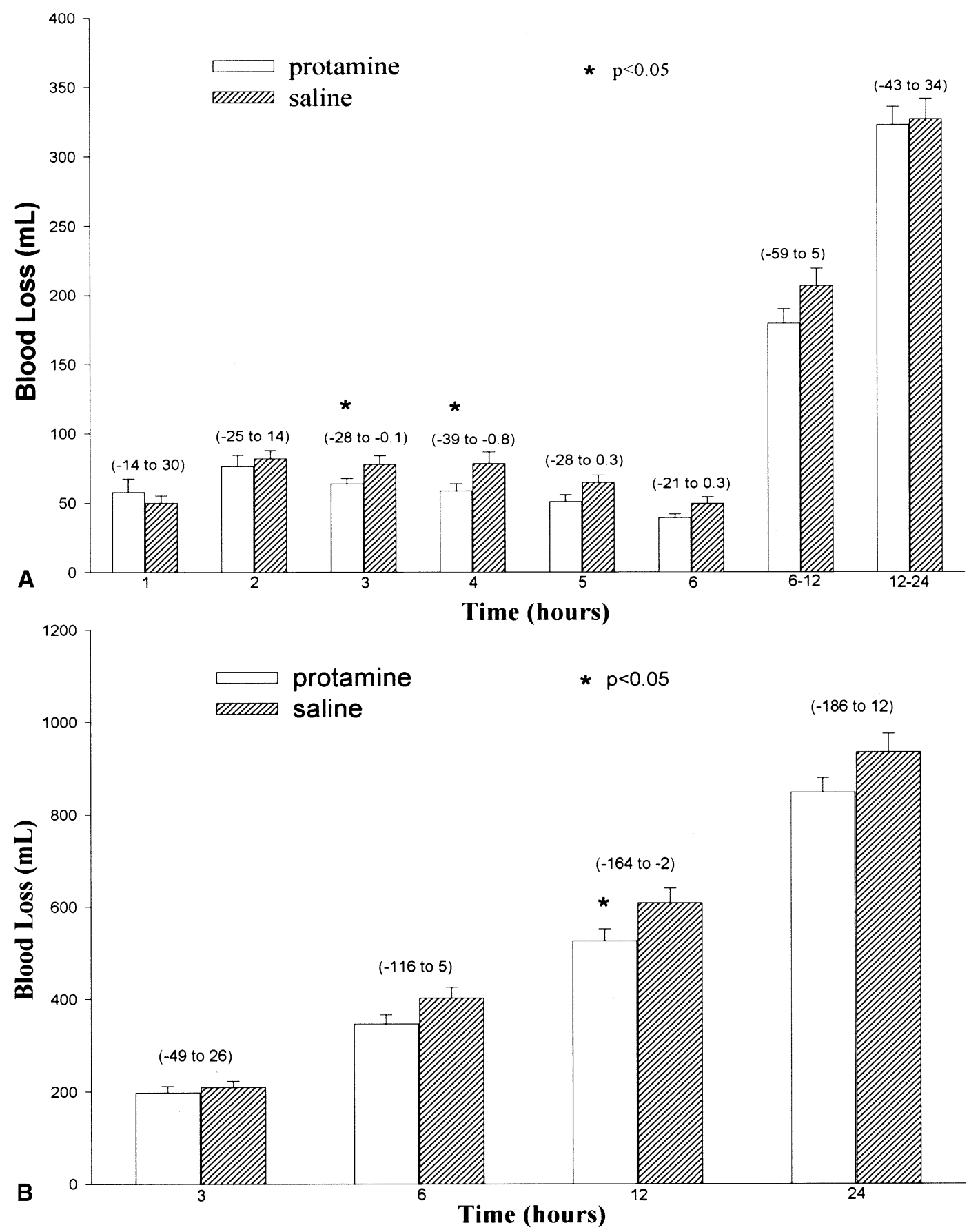

Figure 4. The effect of protamine infusion on blood loss: (A) hourly blood loss; (B) cumulative blood loss. Data are expressed as mean \pm SEM. Values in parentheses represent the $95 \%$ confidence intervals of the difference between group means.

points except 1 hour. The reduction in hourly blood loss between the 2 groups was modest $(5-30 \mathrm{~mL}$ per hour on average) but was significantly different at 3 and 4 hours postoperatively. When expressed as cumulative blood loss
(Figure 4, B), the amount collected during the first 12 hours was significantly lower in the protamine group $(525 \pm 322$ $\mathrm{mL})$ than in the placebo group $(608 \pm 385 \mathrm{~mL})$. The mean reduction in mediastinal blood loss was approximately 80 

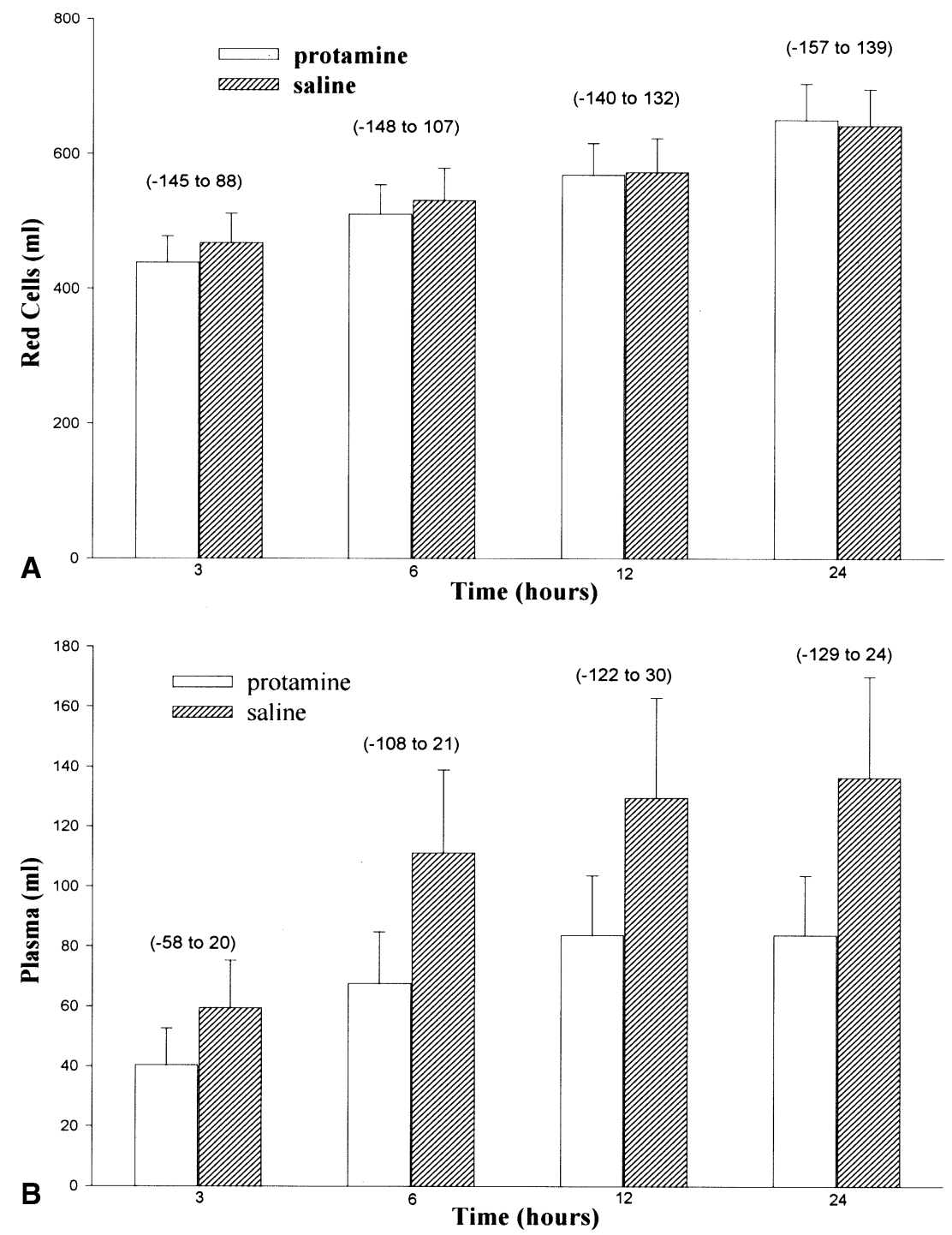

Figure 5. The effect of protamine infusion on transfusion requirements: (A) packed red cells; (B) fresh-frozen plasma. Data are expressed as mean \pm SEM. Values in parentheses represent the $95 \%$ confidence intervals of the difference between group means.

$\mathrm{mL}$, or $13 \%$. At the end of 24 hours, the blood loss in the treatment group was still lower than the placebo group (848 \pm 383 vs $935 \pm 480 \mathrm{~mL}$ ) but the difference was no longer significant. There were no important differences in the hematocrit of the mediastinal drainage fluid or in the patients' hemoglobin values when measured at various times postoperatively. For example, at 1 hour the hematocrit in the chest tube fluid of the placebo group was $0.174 \pm 0.051$ and $0.178 \pm 0.042$ in the protamine group. At 9 hours, the hematocrits were $0.115 \pm 0.064$ and $0.121 \pm 0.064$, respectively. By 12 hours, the hematocrit of the fluid had fallen to $0.076 \pm 0.056$ in the saline group and $0.074 \pm 0.059$ in the protamine group.

\section{Transfusions}

The transfusion requirements are shown in Figure 5. The total volume of packed cells administered to the protamine group was the same as in the placebo group. Sixty-eight percent of patients in both groups received packed cells. For these transfused patients, the protamine group received 950 $\mathrm{mL} /$ patient of packed cells compared to $940 \mathrm{~mL} /$ patient in the saline group. Although there was a trend for the protamine group to need less fresh-frozen plasma, there was no significant difference in cumulative plasma transfusion between the 2 groups. Fifteen percent of patients in the protamine group received fresh-frozen plasma compared with $20 \%$ in the saline group. Of the patients transfused, the 
protamine group received $580 \mathrm{~mL} /$ patient of fresh-frozen plasma versus $690 \mathrm{~mL} /$ patient in the saline group. No patients in the protamine group received platelet transfusions, although $7 \%$ of patients in the placebo group received an average of $250 \mathrm{~mL} /$ patient of platelets.

\section{Discussion}

In this double-blind, randomized study, we have confirmed our earlier observations regarding heparin rebound ${ }^{9}$ but in a much larger patient group. Thus, following heparinization for cardiopulmonary bypass surgery and after neutralization with protamine, heparin rebound was observed in virtually every patient in the placebo group. We propose the following mechanism to explain heparin rebound after protamine neutralization. Heparin binds to AT, to other plasma proteins, to vascular wall matrix proteins, and to endothelial cells where it distributes in an equilibrium that is dependent on the relative affinity of these proteins for heparin binding and the concentrations of the proteins. When protamine is administered, it binds to both unbound heparin and heparin that becomes dissociated from tissue and protein binding sites. The resulting heparin/protamine complexes ${ }^{14}$ are then cleared from the circulation. Heparin rebound occurs because not all heparin is bound to and cleared by protamine. Rather, a proportion remains bound nonspecifically to plasma proteins and vascular cells, which provides a reservoir of heparin that dissociates over time and produces an anticoagulant effect when it binds to AT. ${ }^{9}$

The reappearance of anticoagulant activity in the saline placebo group was indicated by the prolongation of the TcT. The anticoagulant effect was due to heparin because of its effect on anti-factor Xa activity. There was also considerable heparin bound nonspecifically to plasma proteins other than AT. This proportion of protein-bound heparin was unmasked by using low-affinity heparin to displace anticoagulantly active heparin from protein-binding sites. ${ }^{7-9}$ Some of these heparin-binding proteins are acute phase proteins. A number of acute phase reactants including fibronectin, ${ }^{15}$ vitronectin, ${ }^{16}$ and von Willebrand factor ${ }^{17}$ are known to bind heparin. Cardiopulmonary surgery is an inflammatory condition that can stimulate the synthesis of acute phase proteins that could contribute to increased protein binding. ${ }^{18}$

In contrast, the postoperative infusion of protamine ( 25 $\mathrm{mg} / \mathrm{h}$ for 6 hours) was able to eliminate heparin rebound almost completely. The TcTs fell to within normal reference intervals (20-30 seconds). The heparin concentrations measured as anti-factor Xa activity were virtually undetectable and the amount of protein-bound heparin was also dramatically lower in the protamine group. The infusion of small amounts of protamine did not lead to an increase in adverse outcomes.

Unexpectedly, following the termination of the protamine infusion, there was a small but detectable reappear- ance of anticoagulant activity between 9 and 18 hours. This was reflected by increased TcTs, heparin concentration, and protein-bound heparin. It is possible that the extra protamine administered was insufficient to neutralize all the heparin from plasma protein and tissue binding sites because the infusion was terminated prematurely. The pharmacokinetic half-life of protamine is very short (approximately 5 minutes), ${ }^{19}$ and protamine may no longer be present to bind heparin after it is slowly released from non-AT binding sites. Second, heparin has been shown to bind to endothelial cells. ${ }^{20,21}$ A proportion of the bound molecules are internalized and depolymerized into smaller molecular size fragments. Some of the internalized heparin is then secreted in depolymerized form. ${ }^{22,23}$ The persistence of anti-factor Xa activity for several weeks following lowmolecular-weight heparin treatment has been described. ${ }^{24}$ The liver and kidneys were implicated as the tissues that sequester some of the injected drug, which gives rise to anticoagulantly active material by degradation and secretion into the plasma. This tissue reservoir may be inaccessible to protamine. Another factor may be the inability of protamine to completely neutralize low-molecular-weight heparin. ${ }^{25}$ These reasons may help to explain the reappearance of anticoagulant activity once the protamine infusion was stopped. The increase in anticoagulant activity, however, did not increase postoperative bleeding.

The extra protamine administered decreased postoperative bleeding although the magnitude of the reduction was rather modest. The reduced bleeding did not translate into decreased transfusion requirements. Excessive postoperative bleeding after coronary artery bypass surgery is thought to be a multifactorial process. In addition to heparin rebound, hyperfibrinolysis ${ }^{26,27}$ and an acquired platelet defect ${ }^{10}$ are considered to be the main contributors to postoperative bleeding. Antifibrinolytic agents have been employed to reduce postoperative bleeding. These include the protease inhibitor aprotinin and transexamic acid or its analog, epsilon-aminocaproic acid. ${ }^{28,29}$ These drugs have been shown to reduce bleeding by approximately $30 \%$ to $40 \%$ and to reduce allogeneic blood transfusion by a similar amount. ${ }^{30}$ In comparison, our strategy of employing extra protamine to eliminate heparin rebound resulted in only a $13 \%$ reduction in bleeding with no change in transfusion requirements. Our results suggest that heparin rebound is a minor contributor to postoperative bleeding and that activation of the fibrinolytic system plays a greater role.

A potential weakness of our study was that extra protamine $(25-50 \mathrm{mg})$ was given postoperatively to treat clinically significant bleeding in both groups. This cointervention, the extra protamine, was administered concurrently as required along with the blinded study drug. That explains why the placebo group got more protamine for this purpose because they received saline only. We could not ethically 
withhold extra protamine to correct coagulation defects. This may potentially diminish the observed differences in outcomes between the 2 groups. If the unavoidable cointervention had not occurred, the outcome of the study may have been different.

In summary, we have demonstrated that heparin rebound can be virtually eliminated by giving extra protamine for 6 hours during the postoperative period. The procedure is inexpensive. The elimination of heparin rebound led to a statistically significant reduction in postoperative bleeding but the amount of the reduction was modest and did not reduce blood transfusions. The protamine infusion reduces bleeding and appears to be safe although there is insufficient data in the study to rule out uncommon drug-related adverse events. Additional protamine is helpful in the setting of excessive bleeding with evidence of heparin rebound and may be beneficial when used routinely following cardiopulmonary bypass.

K.H.T.T. and E.Y. contributed equally to this study and share first authorship. We acknowledge the participation in this study of the cardiac surgeons, nurses, perfusionists, and the staff of the intensive care unit.

\section{References}

1. Hyun BH, Pence RE, Davila JC, Butcher J, Custer RP. Heparin rebound phenomenon in extracorporeal circulation. Surg Gynecol $\mathrm{Ob}$ stet. 1962;115:191-8.

2. Gollub S. Heparin rebound in open heart surgery. Surg Gynecol Obstet. 1967;124:337-46.

3. Pifarré R, Babka R, Sullivan HJ, Montoya A, Bakhos M, Adel E. Management of postoperative heparin rebound following cardiopulmonary bypass. J Thorac Cardiovasc Surg. 1981;81:378-81.

4. Rosenberg RD, Bauer KA. The heparin-antithrombin system: a natural anticoagulant mechanism. In: Colman RW, Hirsh J, Marder VJ, Salzman EW, editors. Hemostasis and thrombosis: basic principles and clinical practice. 3rd ed. Philadelphia: JB Lippincott Company; 1994. p. 837-60.

5. Lane DA. Heparin binding and neutralizing proteins. In: Lane DA, Lindahl U, editors. Heparin: chemical and biological properties. Boca Raton, Fla: CRC Press; 1989. p. 363-91.

6. Cardin AD, Weintraub HJR. Molecular modeling of protein-glycosaminoglycan interactions. Atherosclerosis. 1989;9:21-32.

7. Young E, Hirsh J. Contribution of red blood cells to the saturable mechanism of heparin clearance. Thromb Haemost. 1990;64:559-63.

8. Young E, Cosmi B, Weitz J, Hirsh J. Comparison of the non-specific binding of unfractionated heparin and low molecular weight heparin (enoxparin) to plasma proteins. Thromb Haemost. 1993;70:625-30.

9. Teoh K, Young E, Bradley CA, Hirsh J. Heparin binding proteins: contribution to heparin rebound after cardiopulmonary bypass. Circulation. 1993;88:420-5.

10. Harker LA, Malpass TW, Branson HE, Hessel EA II, Slichter SJ. Mechanism of abnormal bleeding in patients undergoing cardiopulmonary bypass: acquired transient platelet dysfunction associated with selective $\alpha$-granule release. Blood. 1980;56:824-34.
11. Arén C. Heparin and protamine therapy. Semin Thorac Cardiovasc Surg. 1990;2:364-72.

12. Teien AN, Lie M. Evaluation of an amidolytic heparin assay method: increased sensitivity by adding purified antithrombin III. Thromb Res. 1977; 10:399-410.

13. Casu B, Diamantini G, Fedeli G, Montavani M, Oreste P, Pescador R, et al. Retention of antilipemic activity by periodate-oxidized nonanticoagulant heparins. Arzneim-Forsch/Drug Res. 1986;36:637-42.

14. Butterworth J, Lin YA, Prielipp R, Bennett J, James R. The pharmacokinetics and cardiovascular effects of a single intravenous dose of protamine in normal volunteers. Anesth Analg. 2002;94:514-22.

15. Mosesson MW, Amrani DL. The structure and biological activities of plasma fibronectin. Blood. 1980;56:145-58.

16. Preisnner KT, Muller-Berghaus G. Neutralization and binding of heparin by S-protein/vitronectin in the inhibition of factor Xa by antithrombin III. J Biol Chem. 1987;262:12247-53.

17. Baruch D, Ajzenberg N, Denis C, Legendre P, Lormeau JC, Meyer D. Binding of heparin fractions to von Willebrand factor: effect of molecular weight and affinity to antithrombin III. Thromb Haemost. 1994;71:141-6.

18. Paparella D, Yau TM, Young E. Cardiopulmonary bypass induced inflammation: pathophysiology and treatment. An update. Eur J Cardiothorac Surg. 2002;21:232-44.

19. Butterworth J, Yonggu AL, Prielipp RC, Bennett J, Hammon JW, James RL. Rapid disappearance of protamine in adults undergoing cardiac operation with cardiopulmonary bypass. Ann Thorac Surg. 2002;74:1589-95.

20. van Rijn JLML, Trillou M, Mardiguian J, Tobelem G, Caen J. Selective binding of heparin to human endothelial cells. Implications for pharmacokinetics. Thromb Res. 1987;45:211-22.

21. Young E, Venner T, Ribau J, Shaughnessy S, Hirsh J, Podor TJ. The binding of unfractionated heparin and low molecular weight heparin to thrombin-activated human endothelial cells. Thromb Res. 1999;96: 373-81.

22. Bârzu T, Mohlo P, Tobelem G, Petitou M, Caen J. Binding and endocytosis of heparin by human endothelial cells in culture. Biochim Biophys Acta. 1985;845:196-203.

23. Bârzu T, van Rijn JLML, Petitou M, Tobelem G, Caen JP. Heparin degradation in the endothelial cells. Thromb Res. 1987;47:601-9.

24. Brieger D, Dawes J. Characterization of persistent anti-Xa activity following administration of the low molecular weight heparin enoxaparin sodium (Clexane). Thromb Haemost. 1994;72:275-80.

25. Crowther MA, Berry LR, Monagle PT, Chan AK. Mechanisms responsible for the failure of protamine to inactivate low-molecularweight heparin. Br J Haematol. 2002;116:178-86.

26. Kucuk O, Kwaan HC, Frederickson J, Wade L, Green D. Increased fibrinolytic activity in patients undergoing cardiopulmonary bypass surgery. Am J Hematol. 1986;23:223-9.

27. Teufelsbauer H, Proidl S, Havel M, Vukovich T. Early activation of hemostasis during cardiopulmonary bypass: evidence for thrombin mediated hyperfibrinolysis. Thromb Haemost. 1992;68:250-2.

28. Fremes SE, Wong BI, Lee E, Mai R, Christakis GT, McLean RF, et al. Metaanalysis of prophylactic drug treatment in the prevention of postoperative bleeding. Ann Thorac Surg. 1994;58:1580-88.

29. Laupacis A, Fergusson D. Drugs to minimize perioperative blood loss in cardiac surgery: meta-analyses using perioperative blood transfusion as the outcome. Anesth Analg. 1997;85:1258-67.

30. Henry DA, Moxey AJ, Carless PA, O'Connell D, McCelland B, Henderson KM, et al. Anti-fibrinolytic use for minimising perioperative allogeneic blood transfusion. Cochrane Database Syst Rev. 2001; 1:CD001886. 